\title{
AVALIAÇÃo DE PROCEDIMENTOS DA HIGIENIZAÇÃo DAS MÃOS DOS FUNCIONÁRIOS DE UMA PANIFICAÇÃ̃ DE CAMPINAS - SP
}

\author{
Andréia de Souza Monteiro ${ }^{1}$, Vanessa Fernandes Coutinho², Renato Ribeiro Nogueira Ferraz ${ }^{3}$ \\ Universidade Estácio de Sá - SP.
}

Evaluation of the hands hygienization procedures of servants of a panification of Campinas $S P$

\section{RESUMO}

O estudo é do tipo descritivo e de caráter quantitativo, constituiu com 10 funcionários de uma panificadora de Campinas - SP. O objetivo foi avaliar higienização das mãos durante a produção de pães, bolos e troca de funções. Segundo a Organização Mundial as Saúde (OMS) em 1989 informou que mais do que $60 \%$ das doenças de origem alimentar são DTA'S Doenças Transmitida por alimentos, ou seja, os o agentes etiológicos encontra-se entre as bactérias, vírus, fungos e parasitos, principalmente devido ás práticas inadequadas de manipulação, matérias primas contaminadas, falta de higiene durante a preparação, além de equipamentos e estrutura operacional deficiente e principalmente inadequação no processamento envolvendo o controle de tempo e temperatura, Silva Junior (2016). O resultado apresentado foi que a grande maioria dos funcionários não realizou a higienização das mãos. Conclui-se que mesmo tendo o conhecimento sobre as Boas práticas, ainda existe resistência em praticar o procedimento, prejudicando a segurança e a qualidade dos produtos. Em face do exposto julga-se importante avaliar os procedimentos da higienização das mãos dos funcionários para identificar os riscos de contaminação e qualidade dos produtos.

Palavras-chave: Nutrição. Segurança Nutricional. Higienização. Mãos. Panificação.

\begin{abstract}
The study is of the descriptive type and of quantitative character, constituted with 10 employees of a bakery of Campinas - SP. The objective was to evaluate hand hygiene during the production of breads, cakes and exchange of functions. According to the World Health Organization (WHO) in 1989 reported that more than $60 \%$ of food-borne diseases are transmitted by food, ie the etiological agents are among the bacteria, viruses, fungi and mainly due to improper handling practices, contaminated raw materials, lack of hygiene during preparation, as well as equipment and poor operational structure and mainly inadequate processing involving time and temperature control, Silva Junior (2016). The result was that the vast majority of employees did not perform hand hygiene. It is concluded that even with knowledge about good practices, there is still resistance in practicing the procedure, jeopardizing the safety and quality of the products. In view of the above, it is important to evaluate the hygiene procedures of the employees' hands in order to identify the risks of contamination and product quality.
\end{abstract}

Keywords: Nutrition. Nutritional Security. Hygiene. Hands. Baking.

\section{INTRODUÇÃO}

Nutrição é a ciência que estuda os alimentos, seus nutrientes, bem como sua ação, interação e balanço em relação à saúde e doença, além dos processos pelos quais o organismo ingere, absorve transporta, utiliza e excreta os nutrientes (CUPPARI, 2002). A alimentação e nutrição constituem requisitos básicos para a promoção e a proteção da saúde, possibilitando o crescimento e desenvolvimento humano, com qualidade de vida e cidadania (CAMILO, et al 2016).

Com o aumento da população e diversidade de produtos industrializados e o fato da comida rápida, atualmente se tornou uma constante o consumo de alimentos fora do âmbito 
doméstico, sendo crescente o número de restaurantes e estabelecimentos que comercializam produtos alimentícios (OLIVEIRA, 2016).

De acordo com a Secretária de Vigilância em Saúde (ANVISA), de 2000 a 2011, ocorreram 8.693 surtos causados por bactérias no Brasil, sendo Sthaphylococcus aureus responsável por 799 surtos, ficando abaixo apenas da Salmonela spp. Múltiplos fatores contribuem para o surgimento das DTAs, entre os quais se destacam: o processo de urbanização desordenado, o aumento das populações e consequentemente a necessidade de produção de alimentos em grande escala, a deficiência de fiscalização dos órgãos públicos no setor de alimentação coletiva, a população cada vez mais exposta a alimentos pré-preparados ou prontos para consumo, às mudanças nos hábitos alimentares, falhas durante o processo de higienização dos alimentos e das mãos dos manipuladores (FERNANDES et al 2017).

As boas práticas de fabricação de alimentos (BPF) são estabelecidas pela legislação estabelecimentos que manipulam alimentos. Estas normas compreendem a qualidade da matéria prima, arquitetura dos equipamentos e das instalações, as condições higiênicas do ambiente de trabalho, as técnicas de manipulação dos alimentos e a saúde dos colaboradores, sendo estes fatores importantes para a oferta de alimentos seguros aos consumidores (CAVALHEIRO et al., 2014). Conforme a resolução RDC no 216, de 15 de setembro de 2004, é de extrema importância a higienização das mãos para a redução de microrganismos (ANVISA).

Em face das informações até então apresentados, julga-se importante avaliar os procedimentos de higienização das mãos dos funcionários, de uma panificadora de Campinas - SP, com intuito, de fornecer dados que possam ser utilizados para formulação de acompanhar buscando prevenir a contaminação na manipulação dos alimentos, garantindo a promoção à saúde e produção de produtos com qualidade.

\section{OBJETIVO}

Avaliar o procedimento da higienização das mãos dos funcionários de uma panificadora e esclarecer a importância das boas práticas na manipulação dos alimentos.

\section{MÉTODO}

Foi realizado um estudo observacional do tipo descritivo e de caráter quantitativo em uma panificadora na cidade de Campinas, no período de 05 a 16 de junho de 2017, de segunda a sexta-feira. A pesquisa só foi iniciada após o aceite do proprietário do estabelecimento, e dos participantes só após assinatura do Termo de Consentimento Livre e Esclarecido (TCLE). A amostra foi constituída por 10 funcionários do sexo masculino com idades entre 30 a 48, escolaridade ensino médio completo. Não foi permitida a divulgação de nenhuma informação que pudesse identificar os participantes. Os turnos observados foram o matutino e vespertino da área de produção de panificação e da confeitaria, sendo a equipe dividida em 6 funcionários no período da manhã e 4 funcionários no período vespertino. As coletas de dados foram realizadas no momento da preparação de pães e bolos, e na troca de funções dos funcionários de cada turno no período de três horas a cada dia. Este trabalho atendeu as diretrizes da Resolução 466/2012 do Conselho Nacional de Saúde (CNS), quantos aos aspectos éticos e legais das pesquisas envolvendo seres humanos.

\section{RESULTADO}

A amostra populacional deste estudo foi constituída por 10 funcionários da panificadora. Pode se observar que no primeiro dia, $6(60 \%)$ dos funcionários da panificadora não realizou a higienização das mãos ao manipular os alimentos, e na troca de funções. Somente $04(40 \%)$ realiza a higienização das mãos. No segundo dia, 08 (80\%) dos funcionários da panificadora não realizou a higienização das mãos ao manipular os alimentos, e na troca de funções. Somente $2(20 \%)$ realizou a higienização das mãos. No Terceiro dia, $6(60 \%)$ dos funcionários da panificadora não realizou a higienização das mãos ao manipular os alimentos, e na troca de 
funções. Somente $4(40 \%)$ realizou a higienização das mãos. No quarto dia, $08(80 \%)$ dos funcionários da panificadora não realizou a higienização das mãos ao manipular os alimentos, e na troca de funções. Somente $2(20 \%)$ realizou a higienização das mãos. No quinto dia, 06 $(60 \%)$ dos funcionários da panificadora não realizou a higienização das mãos ao manipular os alimentos, e na troca de funções. Somente $4(40 \%)$ realizam a higienização das mãos. No sexto dia, $06(60 \%)$ os funcionários da panificadora não realizaram ou a higienização das mãos ao manipular os alimentos, e na troca de funções. Somente $4(40 \%)$ realizou a higienização das mãos. No sétimo dia, 8 (80\%) os funcionários da panificadora não realizaram a higienização das mãos ao manipular os alimentos, e na troca de funções. Somente 2 (20\%) realizou a higienização das mãos. No oitavo dia, $6(60 \%)$ dos funcionários da panificadora não realizou a higienização das mãos ao manipular os alimentos, e na troca de funções. Somente 4 (40\%) realizou a higienização das mãos. No nono dia, 6 (60\%) dos funcionários da panificadora não realizou a higienização das mãos ao manipular os alimentos, e na troca de funções. Somente 04 (40\%) realizou a higienização das mãos. No décimo dia, $6(60 \%)$ dos funcionários da panificadora não realizou a higienização das mãos ao manipular os alimentos, e na troca de funções. Somente $4(40 \%)$ realizou a higienização das mãos. Os resultados se encontram resumidos na Figura1.

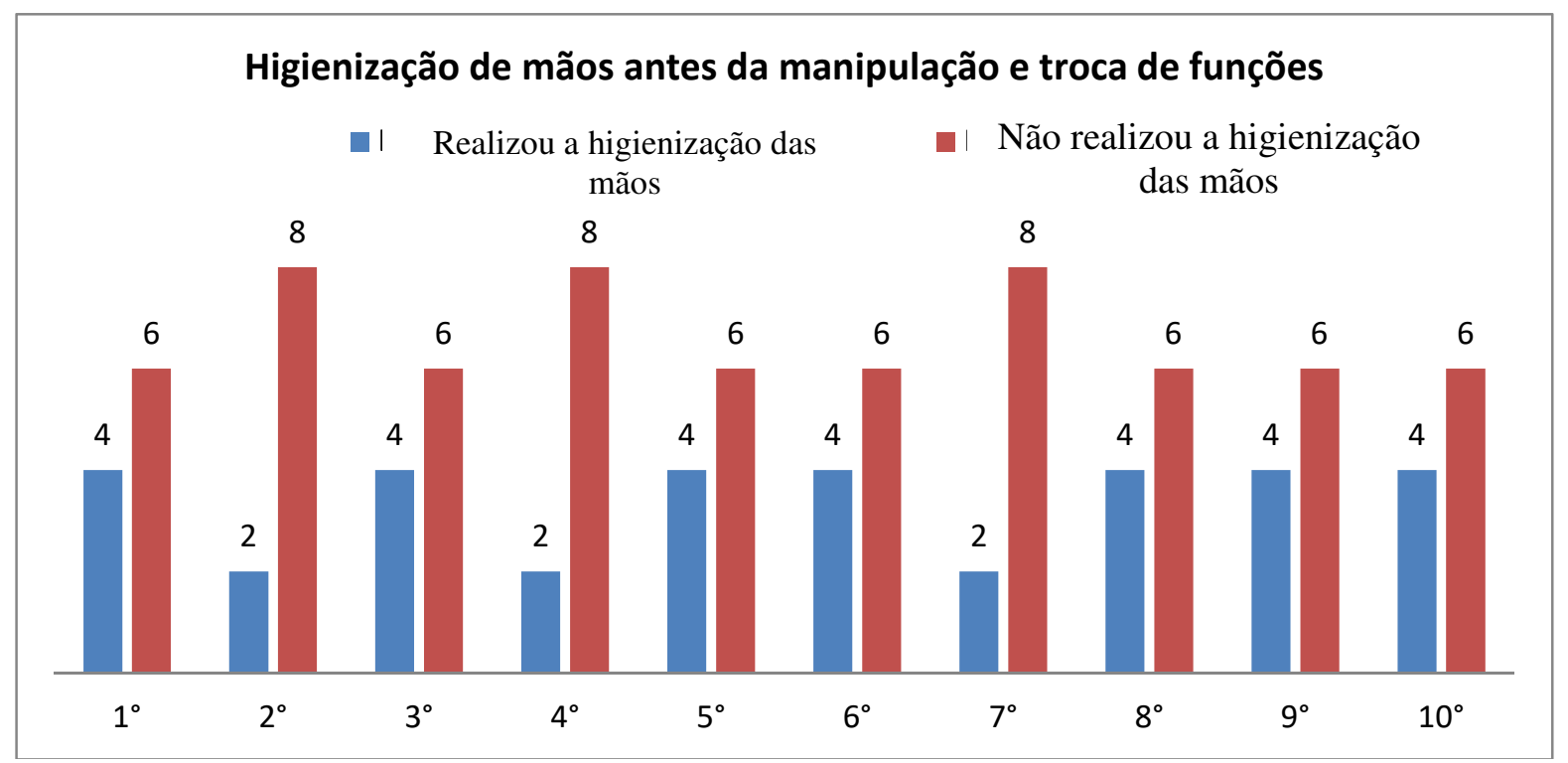

Figura 1: Demonstrativo de higienização de mãos antes da manipulação e troca de funções.

Fonte: Pesquisa de campo, 2017.

\section{DISCUSSÃO}

Neste estudo, observou-se que a grande maioria dos funcionários não realiza a higienização das mãos. Os resultados aqui apresentados estão de acordo com dados publicados por Maciel et al (2016), que em levantamento semelhante realizado na cidade Marabá, Pará, Brasil, em duas panificadoras de médio e pequeno porte.

As avaliações foram realizadas da forma de check-list composto de 90 perguntas com base na RDC n 216/2004, os quesitos abordados foram edificações, instalações, equipamentos, moveis, utensílios, manipuladores, produção, transporte de alimentos e documentação. Os resultados foram da forma de respostas objetivas sim, não e nada consta, constituiu da forma de percentual obtida em cada item analisado. Ressaltando as dificuldades da higienização adequada das mãos que compromete a qualidade dos alimentos e segurança dos consumidores e outros acima abordados.

Reconhece-se que a mostra populacional deste trabalho, assim como o tempo de realização do estudo foram bastante reduzidos. Outros trabalhos que arrolem um maior número de pessoas, com mais tempo de observação, e que comparem os resultados obtidos, entre os 
diversos centros ainda são necessários para a verificação em maior escala do fenômeno observado nesta pesquisa.

\section{CONCLUSÃO}

Os dados obtidos desse trabalho permitem concluir que a maioria dos funcionários da panificadora não realizou o procedimento da higienização das mãos, a carência do cumprimento deste procedimento compromete a qualidade dos alimentos e a segurança dos consumidores. $\mathrm{O}$ estudo apresentou algumas limitações à mostra quantidade populacionais foram reduzidos somente 10 funcionários, o período da coleta somente de uma semana. Sugiro que acerte, mas estudo nesse assunto. Este trabalho sugere que para garantir produtos de qualidade e a comercialização de alimentos, os manipuladores devem ter treinamentos, palestras diárias e um acompanhamento de um responsável técnico que possa implantar o Programa de Boas Práticas de Fabricação - BPF, aliado a intensificação de fiscalização dos órgãos públicos nas panificadoras.

\section{REFERENCIA}

CAMILO, A.M.V. et al; Padrões de Consumo Alimentar em uma cidade do Recôncavo da Bahia: Um enfoque na Segurança Alimentar e Nutricional. O Mundo da Saúde, São Paulo, v. 40, n. 1, p. 51-60, 2016.

CAVALHEIRO, Darlene et al. 4. Treinamento para Manipuladores de Alimentos em Serviços de Alimentação, Pinhalzinho, p.1-6, 2014. Acesso em: 08 de outubro de 2018.

CUPPARI, L. Guia de nutrição clínica no adulto: Guia de nutrição clínica no adulto. Barueri, São Paulo: Manole, 2002. 49p. Acesso: 20 de outubro de 2018.

DE RESENDE, F.R.; FERNANDES, F.M. Incidência de Staphylococcus aureus em mãos de manipuladores de alimentos de unidades de alimentação e nutrição de Leopoldina (MG). Revista Científica da Faminas, v. 12, n. 1, 2017.

OLIVEIRA, K. A. M.; SOUZA, E.C.; COTRIM, W. S. Conhecimento de Boas Práticas de Fabricação em Pizzarias do Município de Barra do Garças-MT. 2013. Trabalho de Conclusão de Curso (Graduação em Engenharia de Alimentos) - Campus Universitário do Araguaia. Acesso em 05 de outubro de 2017. BRASIL. Agência Nacional de Vigilância Sanitária (ANVISA). Resolução RDC nº 216, 15 de setembro de 2004. Regulamento técnico de Boas Práticas para serviço de alimentação. Disponível em: < http://www.anvisa.gov.br/> Acesso: 23 de setembro de 2018.

SILVA JUNIOR, E.A. Manual de Controle Higiênico Sanitário em Serviços de Alimentação: manual de controle higiênico sanitário em serviços de alimentação. 7. ed. São Paulo: Varela, 2016. 163 p. Acesso: 20 de outubro de 2018.

MACIEL, A.R. et al. Verificação das boas práticas de fabricação em panificadoras da cidade de Marabá, Pará, Brasil. Scientia Plena, v. 12, n. 6, 2016. 